\title{
Effect of filler loading on mechanical properties of pultruded kenaf fibre reinforced vinyl ester composites
}

\author{
A.M. Fairuz ${ }^{1}$, S.M. Sapuan ${ }^{1,2,3 *}$, E.S. Zainudin ${ }^{1}$ and C.N.A. Jaafar ${ }^{1}$ \\ ${ }^{1}$ Department of Mechanical and Manufacturing Engineering, \\ Universiti Putra Malaysia, 43400 UPM Serdang, Selangor, Malaysia \\ *Email: sapuan@upm.edu.my \\ Phone: +60389471788; Fax: +60386567122 \\ ${ }^{2}$ Laboratory of Biocomposite Technology, \\ Institute of Tropical Forestry and Forest Products (INTROP), \\ Universiti Putra Malaysia,43400 UPM Serdang, Selangor, Malaysia \\ ${ }^{3}$ Aerospace Manufacturing Research Centre, Faculty of Engineering, \\ Universiti Putra Malaysia, 43400 UPM Serdang, Selangor, Malaysia
}

\begin{abstract}
Pultrusion is one of the polymer composite fabrication processes employing a combination of pulling and extrusion processes. The composite profiles are obtained by pulling resin-impregnated fibres through a series of heated dies. The ability of the pultrusion technique to support a high volume of fibre fraction produces the high stiffness of the composite profile. There are many parameters such as filler loading, mould temperature and pulling speed to be considered and controlled during the pultrusion process. In this paper, an investigation of the effect of the filler loading on the tensile and flexural properties of the pultruded kenaf reinforced vinyl ester composites is presented. As the filler loadings were increased to a significant amount, the mechanical properties started to drop, which was attributed to the increase of viscosity in the matrix and in turn the increase in porosity and decrease in the wettability of the composites. Hence, increasing the amount of filler loading increased the tensile and flexural properties of the pultruded composites in terms of strength and stiffness. The tensile properties of the composites had increased by up to $50 \%$ of fibre loading. The maximum flexural strength and modulus were obtained at 30 and 50\% of filler loadings respectively. The maximum compressive strength was observed to take place at $40 \%$ of filler loading.
\end{abstract}

Keywords: Pultrusion; filler loading; vinyl ester; natural fibre composites; mechanical properties.

\section{INTRODUCTION}

In recent years, natural fibres have been accepted as important reinforcement and filler materials for polymer composites. Natural fibres have been observed to be more environmentally friendly and are better in terms of recyclability, availability and biodegradability compared to synthetic fibres such as carbon, glass and aramid fibres. Not only are these synthetic fibres harmful to health, but it also takes a long time to dispose of the materials [1-4]. Pultrusion is one of the known polymer composite manufacturing processes, which operates by the combination of two techniques; pulling and extrusion processes produce hard and solid composite profiles. It is 
reported by Nosbi et al. [5] that fabrication of high stiffness composite products using a pultrusion process can utilize fibres in which the fibre content exceeds $70 \%$. Pultrusion is a simple technique that has low labour costs and a high production rate [6]. In this process, continuous fibres are impregnated into a resin bath and then squeezed in a guide plate before being cured in a heated die to form a final composite profile. The pultrusion process has the capability to produce different types of continuous profiles such as hollow tubes, bars, beams and any rectangular shape profiles [7]. The pultrusion process uses less energy with a typical production rate of about $3.1 \mathrm{MJ} / \mathrm{kg}$ [8].

Pultrusion has traditionally been used as a composite manufacturing process utilizing synthetic fibres such as glass, carbon and aramid fibres. However, there have been moves in recent years to use natural fibres as reinforcements for polymer composites in the pultrusion process. In the pultrusion process, reinforcement fibres are generally made in a continuous form and similarly so for natural fibres, where the fibres have to be prepared in the form of continuous yarn. Kenaf and jute fibres were reported to be dominating as reinforcements in the pultrusion process involving natural fibres [9-11]. Zamri et al. [12] studied the effect of different types of kenaf yarn fibres on the mechanical properties of pultruded kenaf composites. A study was carried out by Nosbi et al. of compressive properties of pultruded kenaf unsaturated polyester composites after being immersed in various solutions [6]. A study similar to that of Nosbi et al. [5] was performed by Akil et al. [13], who determined the mechanical properties of pultruded jute composites after being immersed in distilled water, sea water and acidic solutions. Another study by Akil et al. [14] was concerned with the effect of water immersion on the mechanical tensile and flexural properties of pultruded jute and hybrid glass/jute fibre reinforced polymer composites. Both studies by Akil et al. $[9,10]$ show that pultruded jute polymer composites have great potential to be used as engineering composite materials in various applications. Omar et al. [15] carried out a study on the determination of the compression properties of pultruded kenaf and jute composites. The compressive properties of pultruded jute composites were found to be superior to those of their kenaf counterparts.

Limited work has been reported on the processing parameters of pultruded natural fibre composites. However, some work has been reported on the processing parameters of the pultrusion process employing conventional fibres like glass and carbon. According to Coelho and Colado, the most critical parameter influencing the pultrusion process is the curing temperature of the composites. Uncured composites may lead to failure of the pultruded composite products. Other important processing parameters include the size of the pultruded profile, the temperature setting, the temperature flowing from the heater to the profile, and the exothermal reaction in the composite molecules [16]. According to Konstantinos et al. [17], the filler type, the amount of filler and the shape of products are the major factors influencing the performance of pultruded composites. The addition of fillers (micro or nano size) in the polymer composites has been found to improve the mechanical properties, especially stiffness or moduli of the composites [7, 18, 19]. This finding was supported by Bassam et al. [20], who state that adding inorganic materials such as calcium carbonate and calcium phosphate will increase the stiffness of the composite materials. Studies of the effect of filler loading on the mechanical properties of the composite material have been carried out by several researchers. Bhattacharya and Bhowmick [21] investigated the swelling behaviour and modulus of the polymer composites. Different prediction formulas have been used to compare the findings with the 
experimental results. Qiang [22] studied the effect of the filler loading of calcium carbonate $\left(\mathrm{CaCO}_{3}\right)$ in high density polyethylene (HDPE) and found an increment of the impact toughness of the composite materials with increase in the filler loading.

Nurdina et al. [23] reported that the particles of the filler increased the tensile strength and modulus in their study of polypropylene composites. Zhou et al. [24] studied the effect of $\mathrm{CaCO}_{3}$ on the mechanical properties of polyether ether ketone (PEEK) composites. The effect of the filler in the extrusion technique was investigated by Fuad et al. [25], whose study showed the improvement in the tensile behaviour of the composites. Hanim et al. [26] studied the behaviour of the filler concentration in the polypropylene (PP) matrix and found improvements from 0 to $15 \%$ of fibre concentration. The result shows an increment of up to $35 \%$ in the acrylonitrile-butadiene-styrene (ABS)-filled $\mathrm{CaCO}_{3}$ [27]. The filler loading has also been reported to affect the flexural strength and modulus [28]. From the above review, it can be concluded that no work has been carried out in the past to study the effect of filler loading on the mechanical properties of pultruded composites either for conventional fibres (glass, carbon and aramid) or for natural fibres. Therefore, in this paper, a study on the effect of the filler loading on the mechanical properties (tensile, flexural and compressive) of the pultruded kenaf reinforced vinyl ester composites is presented.

\section{MATERIALS AND METHODS}

\section{Materials}

Kenaf yarns with 1000 tax were purchased from the Republic of Bangladesh and vinyl ester resin (Swancor 901-3) pultrusion grade was used as a matrix. The technical specifications of the resin are presented in Table 1. Micro size calcium carbonate $\left(\mathrm{CaCO}_{3}\right)$ was used to study the effect of filler loading on the mechanical (tensile, flexural and compressive) properties of kenaf pultruded vinyl ester composites. This filler is selected in the research as a commercial product used to reduce the cost of composites in the industry. The vinyl ester resin was blended with five different filler concentrations: $20 \%, 30 \%, 40 \%, 50 \%$, and $60 \% \mathrm{CaCO}_{3}$ by weight ratio (e.g. $20 \%$ of $\mathrm{CaCO}_{3}$ and $80 \%$ ). A portable Mettler Toledo scale, model WS150VR with maximum capacity of $150 \mathrm{~kg}$ and readability of $0.02 \mathrm{~kg}$ was used to measure the filler and vinyl ester resin. A motor power stirrer was used to mix the formulation matrices for 10 minutes.

Table 1. Properties of vinyl ester resin (Swancor 901-3).

\begin{tabular}{lll}
\hline Properties & Unit & Value \\
\hline Viscosity & $\mathrm{Cps}$ & $450+/-100$ \\
Density & $\mathrm{g} / \mathrm{cm}^{3}$ & 1.04 \\
Tensile strength & $\mathrm{MPa}$ & $80-90$ \\
Tensile modulus & $\mathrm{GPa}$ & $3.2-3.5$ \\
Elongation & $\%$ & $5.0-6.0$ \\
Flexural strength & $\mathrm{MPa}$ & $125-152$ \\
Flexural modulus & $\mathrm{GPa}$ & $3.3-3.8$ \\
\hline
\end{tabular}


Table 2. Composites filler/matrix compositions.

\begin{tabular}{lll}
\hline Sample & Vinyl ester $(\%)$ & $\begin{array}{c}\text { Calcium carbonate } \\
\left(\mathrm{CaCO}_{3}\right)(\%)\end{array}$ \\
\hline $1(20 \%)$ & $8 \mathrm{~kg}$ & $2 \mathrm{~kg}$ \\
$2(30 \%)$ & $7 \mathrm{~kg}$ & $3 \mathrm{~kg}$ \\
$3(40 \%)$ & $6 \mathrm{~kg}$ & $4 \mathrm{~kg}$ \\
$4(50 \%)$ & $5 \mathrm{~kg}$ & $5 \mathrm{~kg}$ \\
$5(60 \%)$ & $4 \mathrm{~kg}$ & $6 \mathrm{~kg}$ \\
\hline
\end{tabular}

\section{Composite Preparation}

Kenaf reinforced vinyl ester composite rods with $10 \mathrm{~mm}$ diameter were produced using the pultrusion process. A pultrusion machine with a capacity of 6 tons of pulling force was used to fabricate the pultruded kenaf composite rods. The fibre reinforcement was pulled through a $10 \mathrm{~mm}$ diameter heated die to produce solid pultruded kenaf composite rods (see Figure 1). The typical composition of the composites and their processing parameters are shown in Table 3.

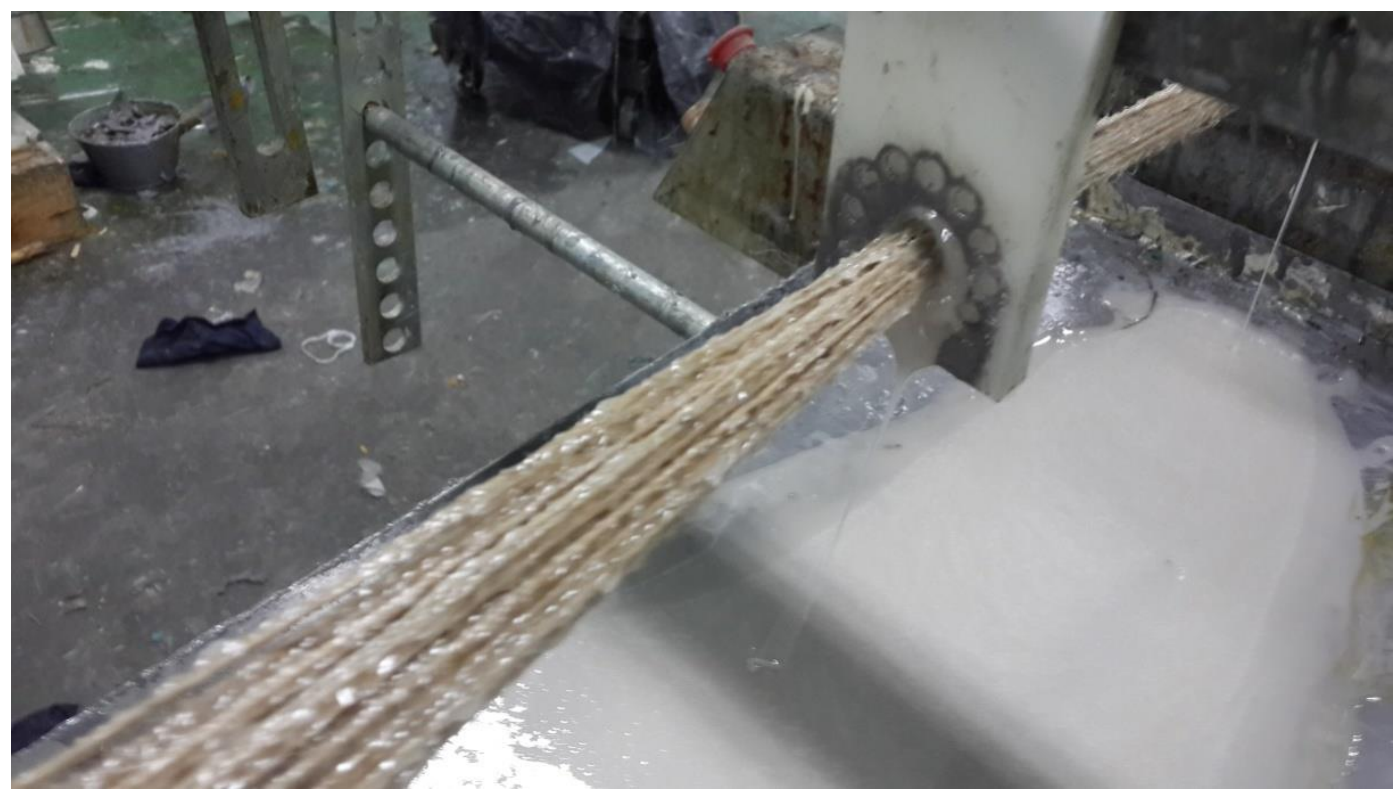

Figure 1. Production of kenaf reinforced vinyl ester composite rod: resinimpregnated fibres were pulled through a guide plate before entering a heated die (courtesy of Innovative Pultrusion Sdn. Bhd., Seremban, Malaysia).

Table 3. Composition of composites and processing parameters.

\begin{tabular}{lll}
\hline Properties & Unit & Value \\
\hline Percentage of matrix & \% by volume & 60 \\
Percentage of fibre & $\%$ by volume & 40 \\
Number of kenaf yarn & Pieces & 50 \\
Density of composite & $\mathrm{g} / \mathrm{cm}^{3}$ & 1.24 \\
Gelation temperature & ${ }^{\circ} \mathrm{C}$ & 120 \\
Curing temperature & ${ }^{\circ} \mathrm{C}$ & 160 \\
Pulling speed & $\mathrm{m} / \mathrm{min}$ & $4 \mathrm{~m} / \mathrm{min}$ \\
\hline
\end{tabular}




\section{Mechanical Properties}

\section{Tensile tests}

The tensile test refers to the ability of a composite material to withstand the forces that tend to pull it apart and to determine to what extent the material stretches before breaking. The tensile properties were determined using a $100 \mathrm{kN}$ Instron 3382 universal testing machine. The tests were carried out at room temperature following the testing method for tensile pultruded glass fibre reinforced plastic rod (ASTM D 3916-02 [29]). The sample length was $250 \mathrm{~mm}$ and the crosshead speed was 5 $\mathrm{mm} / \mathrm{min}$. The samples were prepared with different filler $\left(\mathrm{CaCO}_{3}\right)$ loadings of $20 \%$, $30 \%, 40 \%, 50 \%$, and $60 \%$ and 5 samples were replicated for each loading. The load was applied to the pultruded kenaf composite rods until the maximum tensile load had been obtained.

\section{Flexural tests}

Flexural strength is also known as the modulus of rupture, bead strength, or fracture strength, while the flexural modulus is a measure of the stiffness during the first part of the initial part of the bending process. Good flexural properties of pultruded kenaf composites are very important for the engineering component to avoid failure. Threepoint bending tests were performed according to ASTM D4475-96 standard [30] at room temperature using a $5 \mathrm{kN}$ Instron 4201 universal testing machine with the crosshead speed of $1.3 \mathrm{~mm} / \mathrm{min}$. The sample length was $120 \mathrm{~mm}$ and span length was $100 \mathrm{~mm}$. The samples were prepared with different filler $\left(\mathrm{CaCO}_{3}\right)$ loadings of $20 \%$, $30 \%, 40 \%, 50 \%$, and $60 \%$ and 5 samples were replicated for each loading.

\section{Compressive tests}

Compression is the ability of the composite material to withstand the load tending to resize it. The compressive test was performed at room temperature following the ASTM D695 [31] test method. The pultruded kenaf composite rods were cut to 25.4 mm each and tested using the Instron 4201 universal testing machine with a crosshead speed of $3 \mathrm{~mm} / \mathrm{min}$ (see Figure 2). The samples were prepared with different filler loadings of $20 \%, 30 \%, 40 \%, 50 \%$, and $60 \%$ of $\mathrm{CaCO}_{3}$ and 5 specimens were replicated for each loading.

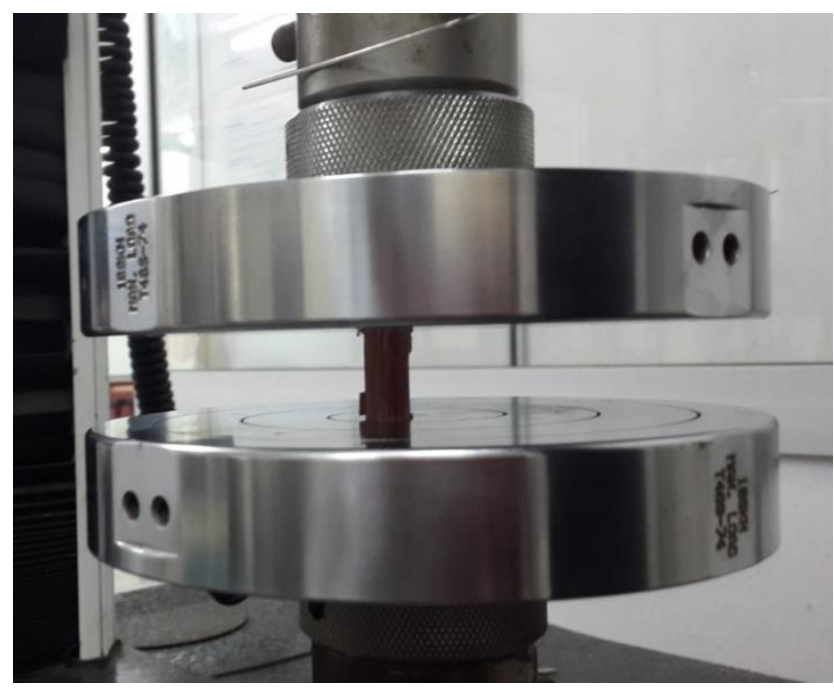

Figure 2. Testing of compressive strength of a pultruded kenaf composite. 


\section{RESULTS AND DISCUSSION}

Figure 3 shows the effect of filler loadings on the tensile strength of the pultruded kenaf composites. Generally, the higher the value of tensile strength of a material, the better the performance of the material will be. When the percentage of the filler was increased, the tensile strength of the pultruded kenaf composites increased by $50 \%$ of filler loading. Beyond that, the tensile strength slightly decreased. As the filler loading was increased from 20 to $50 \%$, the stress was transferred from the vinyl ester matrix to the $\mathrm{CaCO}_{3}$ filler [32] and this situation increased the tensile strength of the pultruded kenaf composites. When the filler loading was increased beyond $50 \%$, the amount of the vinyl ester matrix was insufficient to create the bonding between the kenaf fibre and the vinyl ester matrix. An interstitial volume or an empty gap between spaces full of fillers that resulted from adding more filler caused the tensile strength to decrease at $60 \%$ filler loading [33]. The reduction in strength was also due to the squeezing stress during the fibre impregnation process. The increase of the fillers caused the viscosity of the vinyl ester matrix to increase and it reduced the penetration rate of the matrix into the kenaf yarn.

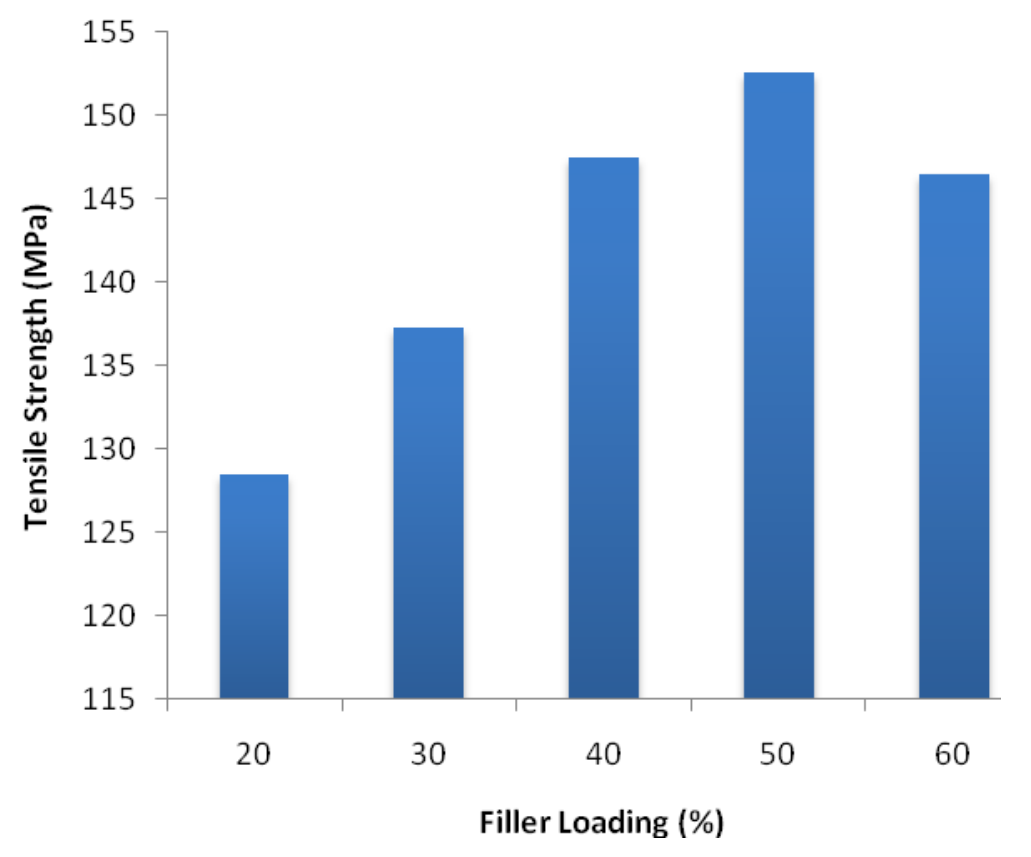

Figure 3. The effect of filler loading on tensile strength of pultruded kenaf composites.

As far as the tensile modulus is concerned, Figure 4 shows that there has been a constant increase in tensile modulus from 20 to $50 \%$ of filler loading, as in the case of tensile strength. The filler acts as a barrier to the propagation of micro-cracks and imparts a higher flexural modulus. The filler is stiffer than the matrix and it deforms less, causing an overall reduction in matrix strain, especially in the vicinity of the particles as a result of the particle matrix interface [33]. The maximum value of tensile modulus for this pultruded kenaf composite is at $50 \%$ filler loading. Similar trends were observed in the $\mathrm{ABS}$ filled with $\mathrm{CaCO}_{3}$, but the maximum stiffness was obtained at $35 \%$ of filler loading and in PP filled with $\mathrm{CaCO}_{3}$, with the maximum modulus at $40 \%$ filler loading $[23,27]$. However, beyond $50 \%$, there was a slight decrease in the 
modulus. This finding is in agreement with results of Zhou et al. [24]. The addition of filler increased the stiffness of the composites, but as the amount of filler was increased beyond $50 \%$, a reduction in the modulus was observed. In this situation, the vinyl ester matrix became more viscous and, as in the case of tensile strength, it reduced the penetration rate of the matrix into the kenaf yarn, thus reducing the stiffness. In addition, increasing the amount of filler increased the porosity in the composites [20], and it reduced the wettability between fibre and matrix, thus reducing the stiffness of the composites. At very high filler loading, the behaviour of composites changed from ductile to brittle, as reported by Fu et al. [18].

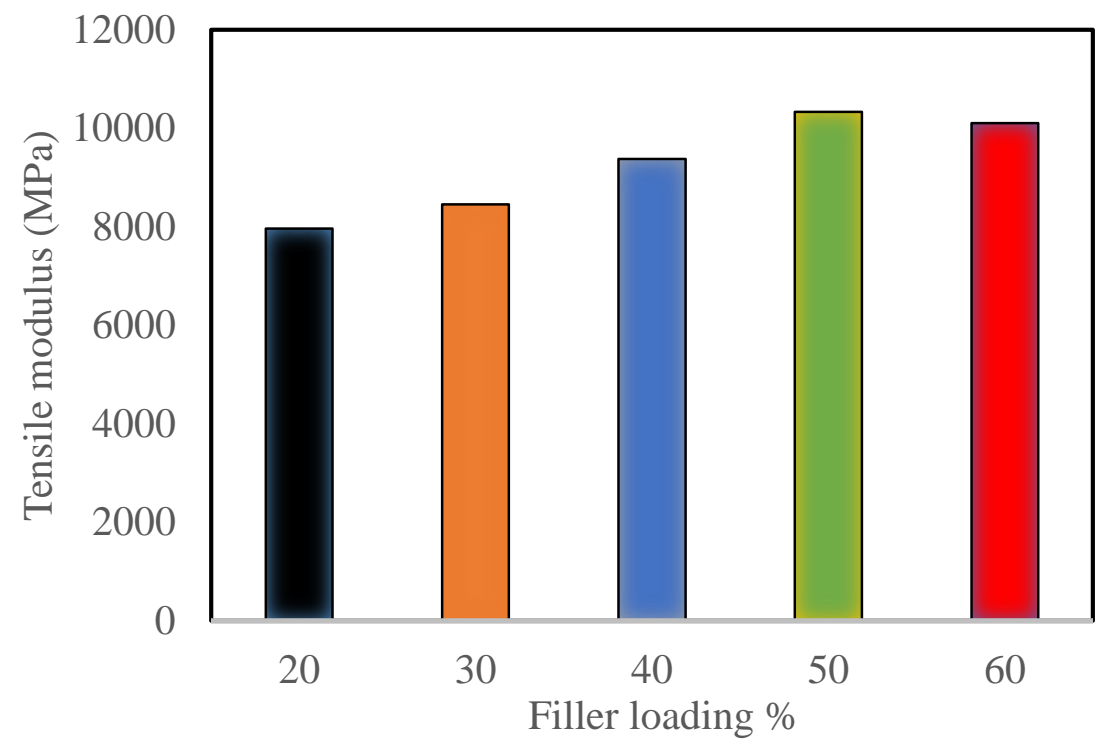

Figure 4. Effect of filler loading on tensile modulus of pultruded kenaf composites.

Flexural strength or bending strength is defined as the maximum load applied in the horizontal condition. The flexural strength behaviour in Figure 5 shows the increment from 20 to $30 \%$ (maximum flexural strength) of filler loading and then drops from $60 \%$ of the filler loading. The trend is similar to the finding of Tong et al. [34], where the flexural strength increased from 0 to $30 \%$ of filler loading and then the strength dropped from $40 \%$ of filler loading. Mitchell [35] explained that the viscosity of the matrix affected the wettability of the composites in the pultrusion process. At the filler loading from 20 to $30 \%$, the viscosity of the matrix was still low. The high viscosity of the matrix due to the addition of more filler caused the presence of porosity in the composites and in turn caused the wettability between fibres and matrix to become poor. The presence of more porosity had reduced the flexural strength of the pultruded kenaf composites. The results of the flexural modulus are shown in Figure 6. The flexural modulus increased when the filler loading was increased to $50 \%$ (maximum modulus) and then the modulus decreased from 50 to $60 \%$. A trend similar to that of the tensile modulus (Figure 4) is observed. The increase of $\mathrm{CaCO}_{3}$ in the matrix had increased the elastic moduli of the composites due to the rigidity of the filler and the strong interaction between the filler and the polymer matrix [36]. 


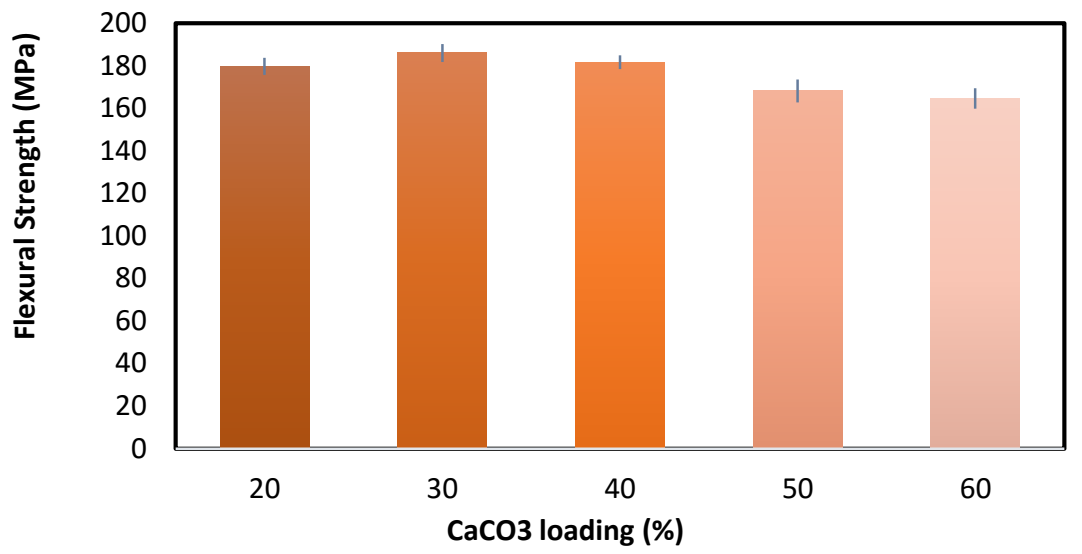

Figure 5. Flexural strength of pultruded kenaf composites with different filler loadings.

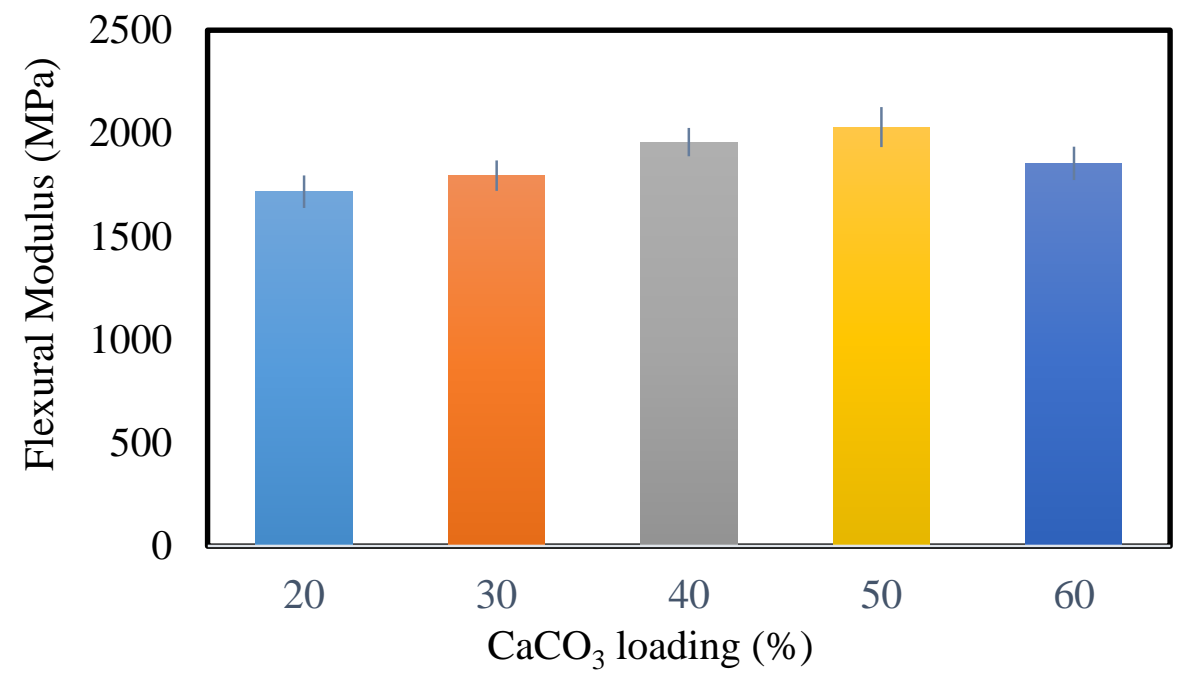

Figure 6. Flexural modulus of pultruded kenaf composites with different filler loadings.

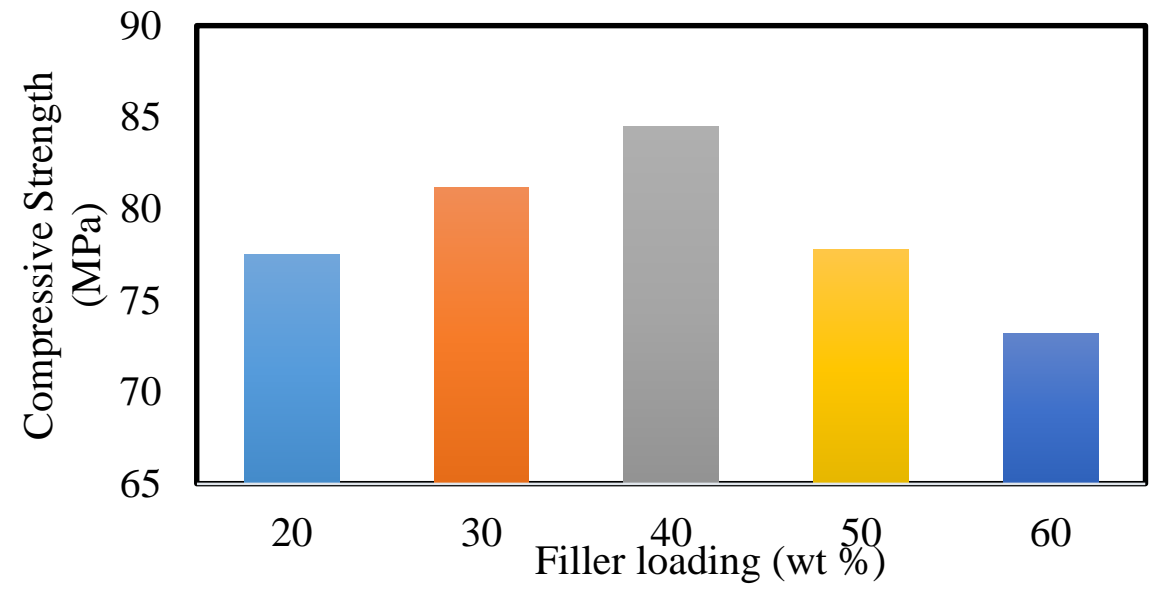

Figure 7. Compressive strength of kenaf pultruded composites with different filler loadings. 


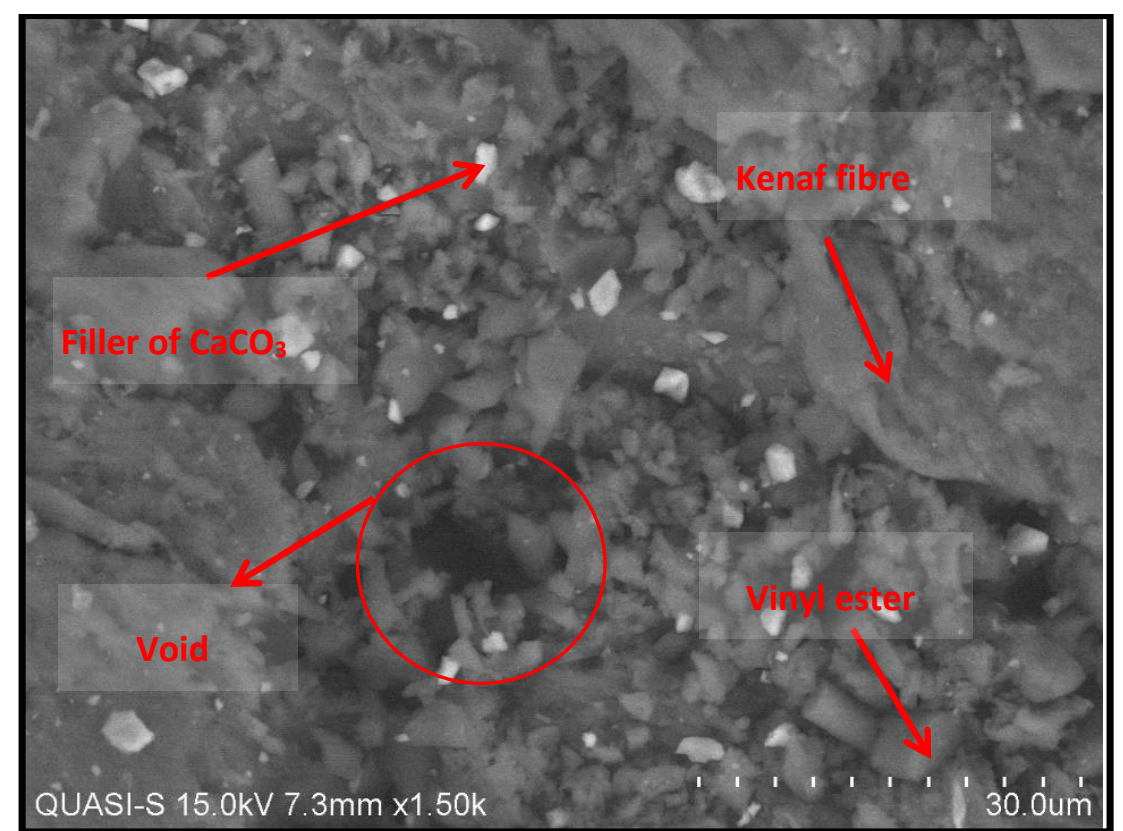

(a)

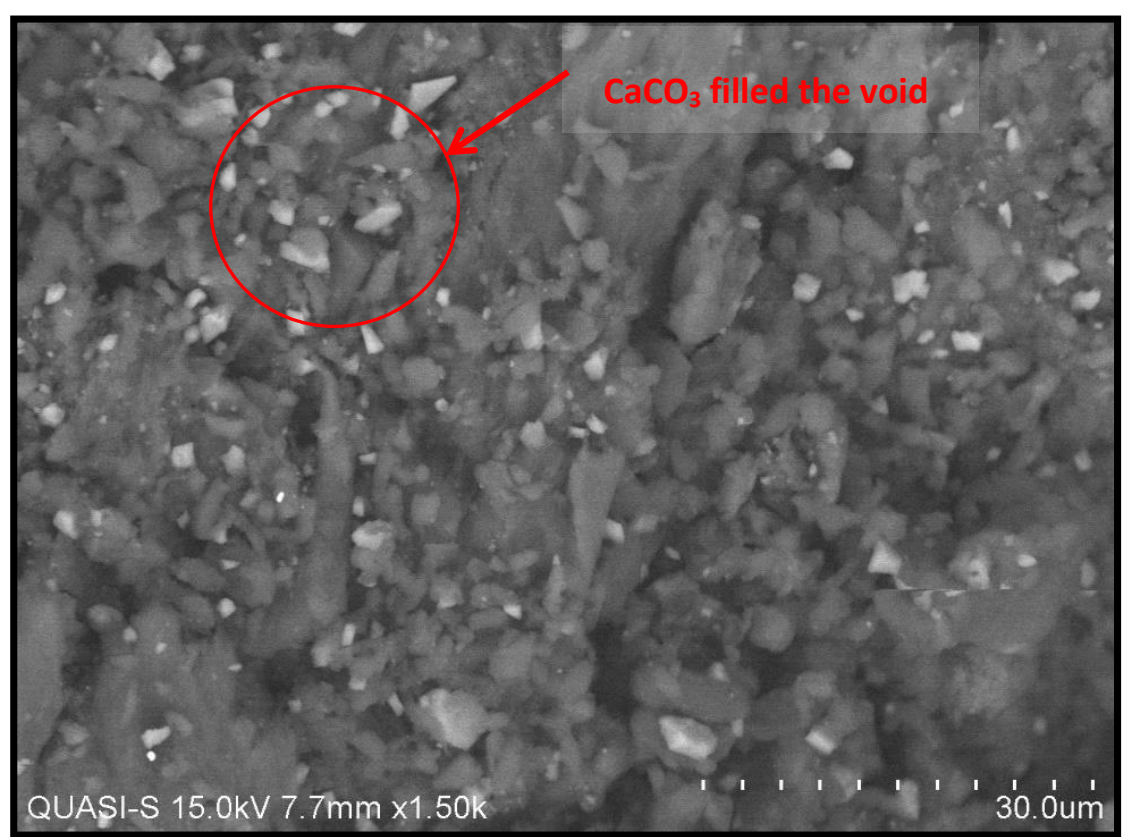

(b)

Figure 8. Scanning electron micrographs (SEM) of pultruded kenaf composites for (a) $30 \%$ filler loading and (b) $50 \%$ filler loading.

Figure 7 shows the results of the compressive strength of pultruded kenaf composites at different filler loadings. The compressive strength of the pultruded kenaf composites increased from 20 to $40 \%$ of filler loadings. Filler particulates in the composites had the function of impeding the movement of cracks, and this led to the increase in the compressive strength of the composites [37]. The compressive strength of the pultruded kenaf composite rod attained the maximum compressive strength at $40 \%$ of filler loading. At this loading the maximum wetting between the filler, matrix and fibre was observed. Then the compressive strength decreased dramatically from 40 to $60 \%$ of the filler loading. This dramatic drop in strength may 
be related to the increase in the viscosity of the matrix (increase in surface energy of the matrix), which reduced filler wetting and led to the emergence of a lot of flaws and gaps within the composites [37]. The SEM images of the fractured surfaces of tensile specimens of pultruded kenaf reinforced vinyl ester composites are shown in Figure 8. In Figure 8(a) the $\mathrm{CaCO}_{3}$ loading is $30 \%$ and in Figure 8(b) the filler loading is $50 \%$. Figure 8 (a) shows the significant number of voids that occurred between the kenaf fibres and the matrix. Even if some amount of $\mathrm{CaCO}_{3}$ filler had filled the voids, there were still very many voids remaining in the samples. However, in Figure 8(b) the majority of voids are filled with the filler.

\section{CONCLUSIONS}

In this paper, a study on the effect of filler loading on the mechanical properties of pultruded kenaf reinforced vinyl ester composites is presented. The tensile, flexural and compressive properties of the composites have been analysed and the results show that increase in the filler loading improved the mechanical properties of the composites. As the filler loadings were increased to a significant amount, the mechanical properties started to drop, which was attributed to the increase of viscosity in the matrix and in turn the increase in porosity and decrease in wettability in the composites. The limitation on kenaf pultruded composites, especially in selecting and defining the parameter values, needs to be overcome by collaboration between the industry and research institutes for future study. Other parameters such as the curing temperature, pressure inside the die length and pulling speed should also be investigated and studied.

\section{ACKNOWLEDGEMENTS}

The authors would like to thank MrRasidinSenawi and MrRozaimiSenawi of Innovation PultrusionSdn. Bhd., Seremban, Malaysia, for their assistance in the fabrication of pultruded kenaf vinyl ester composites, in preparing polymer formulation and in the fibre fraction design. The authors are also indebted to Universiti Putra Malaysia for the providing research funding through Research University Grant Scheme (RUGS) with the project number RUGS 2-2012-05-02-121916RU.

\section{REFERENCES}

[1] Sastra H, Siregar J, Sapuan SM, Hamdan M. Tensile properties of Arenga pinnata fiber-reinforced epoxy composites. Polymer-Plastics Technology and Engineering. 2006;45:149-55.

[2] Rashdi A, Sapuan S, Ahmad M, Khalina A. Water absorption and tensile properties of soil buried kenaf fibre reinforced unsaturated polyester composites (KFRUPC). Journal of Food, Agriculture \& Environment. 2009;7:0.

[3] Leman Z, Sapuan SM, Azwan M, Ahmad MMHM, Maleque M. The effect of environmental treatments on fiber surface properties and tensile strength of sugar palm fiber-reinforced epoxy composites. Polymer-Plastics Technology and Engineering. 2008;47:606-12.

[4] Abdul Majid MS, Daud R, Afendi M, Amin NAM, Cheng EM, Gibson AG, et al. Stress-strain response modelling of glass fibre reinforced epoxy composite pipes 
under multiaxial loadings. Journal of Mechanical Engineering and Sciences. 2014;6:916-28.

[5] Nosbi N, Akil HM, Ishak ZM, Bakar AA. Degradation of compressive properties of pultruded kenaf fiber reinforced composites after immersion in various solutions. Materials \& Design. 2010;31:4960-4.

[6] Sharma D, McCarty T, Roux J, Vaughan J. Fluid mechanics analysis of a twodimensional pultrusion die inlet. Polymer Engineering \& Science. 1998;38:161122.

[7] Fairuz A, Sapuan S, Zainudin E, Jaafar CNA. Optimization of pultrusion process for kenaf fibre reinforced vinyl ester composites. Applied Mechanics and Materials: Trans Tech Publ; 2015. p. 499-503.

[8] Song YS, Youn JR, Gutowski TG. Life cycle energy analysis of fiber-reinforced composites. Composites Part A: Applied Science and Manufacturing. 2009;40:1257-65.

[9] Fatchurrohman N, Sulaiman S, Sapuan SM, Ariffin MKA, Baharuddin BTHT. Analysis of a metal matrix composites automotive component. International Journal of Automotive and Mechanical Engineering. 2015;11:2531-40.

[10] Wan Dalina WAD, Mariatti M, Mohd Ishak ZA, Mohamed AR. Comparison of properties of MWCNT/carbon fibre/ epoxy laminated composites prepared by solvent spraying method. International Journal of Automotive and Mechanical Engineering. 2014;10:1901-9.

[11] Othman RN, Wilkinson AN. The impedance characterization of hybrid cnt-silica epoxy nanocomposites. International Journal of Automotive and Mechanical Engineering. 2014;10:1832-40.

[12] Zamri MH, Md Akil H, Mohd Ishak Z, Abu Bakar A. Effect of different fiber loadings and sizes on pultruded kenaf fiber reinforced unsaturated polyester composites. Polymer Composites. 2015;36:1224-9.

[13] Akil HM, Cheng LW, Ishak ZM, Bakar AA, Rahman MA. Water absorption study on pultruded jute fibre reinforced unsaturated polyester composites. Composites Science and Technology. 2009;69:1942-8.

[14] Akil HM, De Rosa IM, Santulli C, Sarasini F. Flexural behaviour of pultruded jute/glass and kenaf/glass hybrid composites monitored using acoustic emission. Materials Science and Engineering: A. 2010;527:2942-50.

[15] Omar MF, Akil HM, Ahmad ZA, Mazuki A, Yokoyama T. Dynamic properties of pultruded natural fibre reinforced composites using Split Hopkinson Pressure Bar technique. Materials \& Design. 2010;31:4209-18.

[16] Coelho R, Calado V. An optimization procedure for the pultrusion process based on a finite element formulation. Polymer Composites. 2002;23:329-41.

[17] Masouras K, Silikas N, Watts DC. Correlation of filler content and elastic properties of resin-composites. Dental Materials. 2008;24:932-9.

[18] Fu S-Y, Feng X-Q, Lauke B, Mai Y-W. Effects of particle size, particle/matrix interface adhesion and particle loading on mechanical properties of particulatepolymer composites. Composites Part B: Engineering. 2008;39:933-61.

[19] Fairuz A, Sapuan S, Zainudin E, Jaafar C. Polymer composite manufacturing using a pultrusion process: a review. American Journal of Applied Sciences. 2014;11:1798.

[20] Bassam F, York P, Rowe R, Roberts R. Young's modulus of powders used as pharmaceutical excipients. International Journal of Pharmaceutics. 1990;64:5560. 
[21] Bhattacharya M, Bhowmick AK. Polymer-filler interaction in nanocomposites: new interface area function to investigate swelling behavior and Young's modulus. Polymer. 2008;49:4808-18.

[22] Qiang F. Effect of morphology on brittle-ductile transition of HDPE/CaCO3 blends. Journal of Applied Polymer Science. 1993;49:673-7.

[23] Nurdina A, Mariatti M, Samayamutthirian P. Effect of single-mineral filler and hybrid-mineral filler additives on the properties of polypropylene composites. Journal of Vinyl and Additive Technology. 2009;15:20-8.

[24] Zhou B, Ji X, Sheng Y, Wang L, Jiang Z. Mechanical and thermal properties of poly-ether ether ketone reinforced with $\mathrm{CaCO} 3$. European Polymer Journal. 2004;40:2357-63.

[25] Fuad M, Hanim H, Zarina R, Ishak ZM, Hassan A. Polypropylene/calcium carbonate nanocomposites-Effects of processing techniques and maleated polypropylene compatibiliser. eXPRESS Polym. eXPRESS Polymer Letters. 2010;4:611-20.

[26] Hanim H, Zarina R, Fuad MA, Mohd Z, Ishak AH. The effect of calcium carbonate nanofiller on the mechanical properties and crystallisation behaviour of polypropylene. Malaysian Polymer Journal. 2008;3:38-49.

[27] Jiang L, Lam Y, Tam K, Chua T, Sim G, Ang L. Strengthening acrylonitrilebutadiene-styrene (ABS) with nano-sized and micron-sized calcium carbonate. Polymer. 2005;46:243-52.

[28] Kim K-H, Ong JL, Okuno O. The effect of filler loading and morphology on the mechanical properties of contemporary composites. The Journal of Prosthetic Dentistry. 2002;87:642-9.

[29] International A. Standard test method for tensile properties of pultruded glassfiber reinforced plastic rod.West Conshohocken (PA). ASTM 3916-12: ASTM International; 2002.

[30] International A. Standard test method for flexural properties of fibre reinforced pultruded plastic rods. West Conshohocken (PA). ASTM D4475-96: ASTM International; 1997.

[31] International A. Annual Book of ASTM Standard. Volume 08.01 plastics (I). West Conshohocken (PA). ASTM D256-D3159. ASTM International; 2005.

[32] Vincent SR, Jaafar M, Palaniandy S. Properties of calcium carbonate/MICA and calcium farbonate/talc filled polypropylene composites. Journal of Engineering Science. 2014;10:41.

[33] Borkar SP, Kumar VS, SS M. Effect of silica and calcium carbonate filler on the properties of woven fibre composites. India Journal of Fibre Textile Resource 2007;32:251-3

[34] Tong JY, Royan NRR, Ng YC, Ab Ghani MH, Ahmad S. Study of the mechanical and morphology properties of recycled HDPE composite using rice husk filler. Advances in Materials Science and Engineering. 2014;2014.

[35] Mitchell BS. An introduction to materials engineering and science for chemical and materials engineers: John Wiley \& Sons; 2004.

[36] Chen N, Wan C, Zhang Y, Zhang Y. Effect of nano- $\mathrm{CaCO}_{3}$ on mechanical properties of PVC and PVC/Blendex blend. Polymer Testing. 2004;23:169-74.

[37] Hanna WA, Gharib FE, Marhoon II. Characterization of ceramic filled polymer matrix composite used for biomedical applications. Journal of Minerals and Materials Characterization and Engineering. 2011;10:1167. 